\title{
PSYCHE
}

\begin{tabular}{lll}
\hline Vol. 84 & June, 1977 & No. 2 \\
\hline
\end{tabular}

\section{PAIRING BEHAVIOR IN HODOTERMES MOSSAMBICUS (ISOPTERA) ${ }^{1}$}

\author{
BY R. H. LEUTHOLD22 AND O. BRUINSMA
}

Division of Animal Physiology, Zoological Institute, University of Bern, Engehaldenstr. 6, CH-3012 Bern, Switzerland; and The International Center of Insect Physiology and Ecology, P.O. Box 30772, Nairobi, Kenya

\section{INTRODUCTION}

The dispersal flight of termites, especially of those species living in savannah areas with alternating dry and wet seasons, is generally related to the beginning of a rainy period. The precise time of flight may be controlled by exogenous or endogenous factors and varies from species to species. Most species fly at dawn or dusk or at night whereas the few daylight-fliers usually swarm only under humid atmospheric conditions. After individual landing the alates of both sexes will meet in pairs. A typical "calling" posture of the female was observed in many species and was interpreted by several authors as chemical attraction. However, no precise evidence for this interpretation was given from field observations and no data about the spatial range of attraction were specified. After meeting, the sexes of many species proceed in "tandem", a typical formation, in which the male usually follows the female closely on the search for a suitable nesting site. The termite considered herein, Hodotermes mossambicus, is a dry grass harvesting species, exceptionally adapted to survive under extreme climatic conditions of semi-arid grasslands. The species differs in several aspects from other termites: the workers forage in relatively loose formation above ground often in sunshine and are able to use individual op-

\footnotetext{
${ }^{1}$ Research supported by the Swiss National Foundation, grant no. 3.2810.74.

${ }^{2} \mathrm{~A}$ short summary of this subject is part of a communication presented in Proc. VIII Congr. IUSSI 1977, Wageningen.

Manuscript received by the editor November 28, 1977.
} 
tical orientation in contrast to the usual feature of foraging columns confined under galleries or in narrow pheromone trails (Leuthold et al., 1976). In contrast to other termites, they have functional compound eyes and darkly pigmented body surface. Alate imagines and workers carry their own water supply in specialized water sacs, according to Watson et al. (1971). We had the opportunity to observe carefully the pairing behavior of $H$. mossambicus on a single swarming day (9.4.1976) in Olorgesailie, Kenya. This study revealed an unusual modification also in the pattern of pairing behavior. The reproductive dispersal flight occurs during the hot period in the afternoon, often during full sunshine on the day after a rainfall. The roles of male and female were found reversed relative to the behavior observed in other termites. A mechanism of pheromonal sex attraction was clearly concluded from the behavior. Unfortunately, another flight during which we expected to carry out planned experimental analysis did not occur during our available observation time.

\section{OBSERVATIONS}

The climate of Olorgesailie, the area of observation in the great Rift Valley near Nairobi, is characterized by extensive dry periods and sporadic rainfall of $300-400 \mathrm{~mm}$ per year, concentrated in the months of February to May and to a lesser extent from October to November. Swarming of $H$. mossambicus in this area takes place after substantial rainfall following the main dry season (recorded data of rainfall that released flight: $1.3 \mathrm{~mm}, 35 \mathrm{~mm}$ and $21.2 \mathrm{~mm}$ ). In this area the swarming often extends over several rains if the showers are only weak and sporadic. Swarming was recorded on (23.12.1971), 8.1.1973, 25.2.1973, (20.2.1974), 9.4.1976 and 3.4.1977.3 The time of swarming recorded was always in the afternoon under sunny conditions on the day following rainfall. One expected flight did not occur with overcast sky and slight drizzle. ${ }^{4}$

\footnotetext{
${ }^{3}$ Partly recorded by Mr. Kannugi, warden at the prehistoric site in Olorgesailie. The figures in parentheses are not well documented.

${ }^{4}$ Hewitt and Nel (1969) reported flight after a latency time of 4 to 6 days after the first substantial summer rains, in the Orange Free State in South Africa. They did not mention the meteorological conditions before and during flight. It seems worthwhile to collect more data in both areas to decide whether the populations in the two zones of very different latitude $\left(1.6^{\circ} \mathrm{S}\right.$ and $\left.29^{\circ} \mathrm{S}\right)$ behave differently in this respect.
} 
The swarming referred to in this paper occurred on 9.4.1976 around $16.30 \mathrm{~h}$ (sunshine). After a short dispersal flight of less than $100 \mathrm{~m}$ the alates landed individually on the ground, shed their wings and started running about. [Behavioral details of this sequence have been described by Hewitt and Nel, 1969.] The MALES rambled with their abdomens raised in "calling" position and their huge sternal glands exposed (Fig. 1) in search of a digging ground. If they found a suitable place, they started excavating a hole by flicking dust particles out with their legs and often carrying out soil bits with their mandibles. They held their abdomens permanently in "calling" posture as long as they were unpaired. The unpaired FEMALES, on the other hand, repeatedly climbed on elevated structures, such as grass stems, apparently for "sniffing" for the male's scent. They clearly perceived the presence of a male from a distance of at least $2.5 \mathrm{~m}$ up-wind. They obviously became excited and ran slightly zig-zag towards the calling male, without ever failing to reach the goal (Fig. 2). The joining of a female with a digging male was analyzed from two film sequences: the female touched the male's abdomen with her antennae. On this stimulus the male turned around through $180^{\circ}$ and palpated the female's abdomen intensively. With that stimulus, apparently, the male terminated calling behavior by lowering the abdomen and retracting the sternal gland. Henceforth, no other female was attracted, not even from as close as a few $\mathrm{cm}$. The pair met either during the male's exploratory run or on the male's digging site. In the latter case the female participated in excavating behavior. In the first case she followed him in loose formation on the search for digging terrain. However, no rigid pattern such as that referred to as "tandem run" was ever observed. In suitable ground the digging pair disappeared from the surface within minutes. If the substrate was too hard or if the pair was attacked by ants, the male went on in search of another place, followed by the female. In the postflight behavior the male was always the attracting and leading partner and the female actively hunted for him. If the female was experimentally removed from the pair, the male resumed calling behavior. However, reproductives collected in petridishes did not resume sex attraction behavior when separated and tested the day after flight in the laboratory nor did a crushed male sternal gland under those conditions attract any female. 

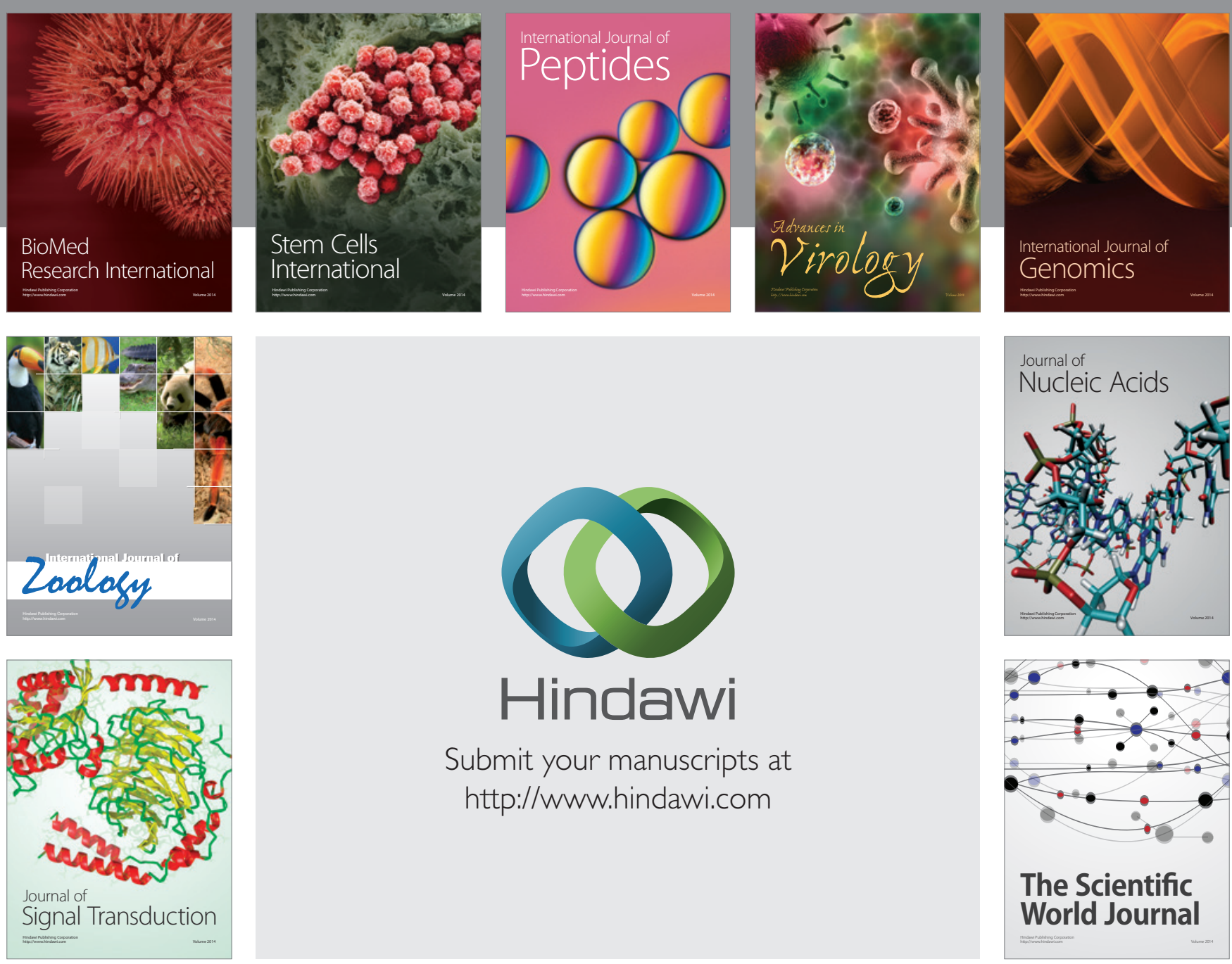

Submit your manuscripts at

http://www.hindawi.com
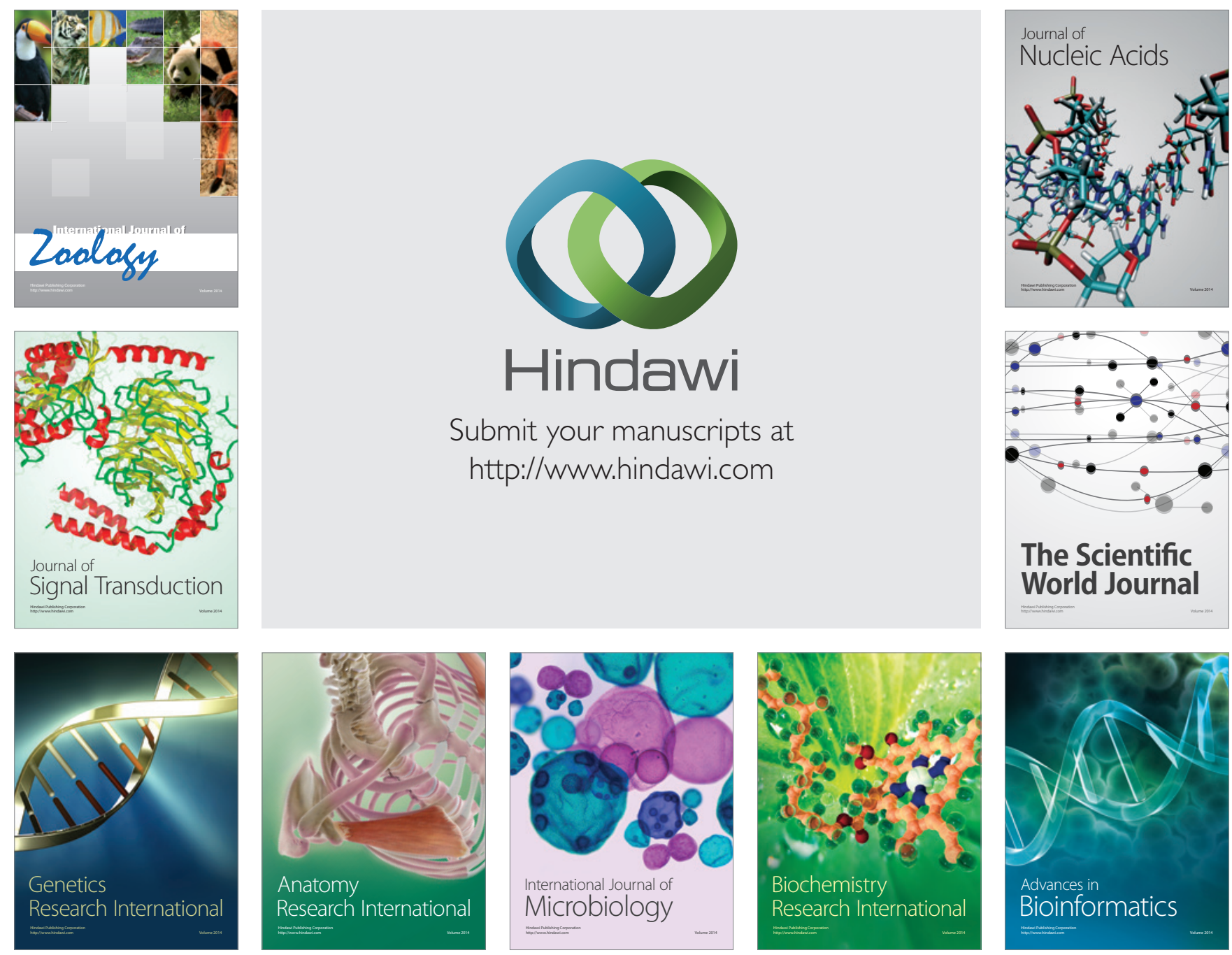

The Scientific World Journal
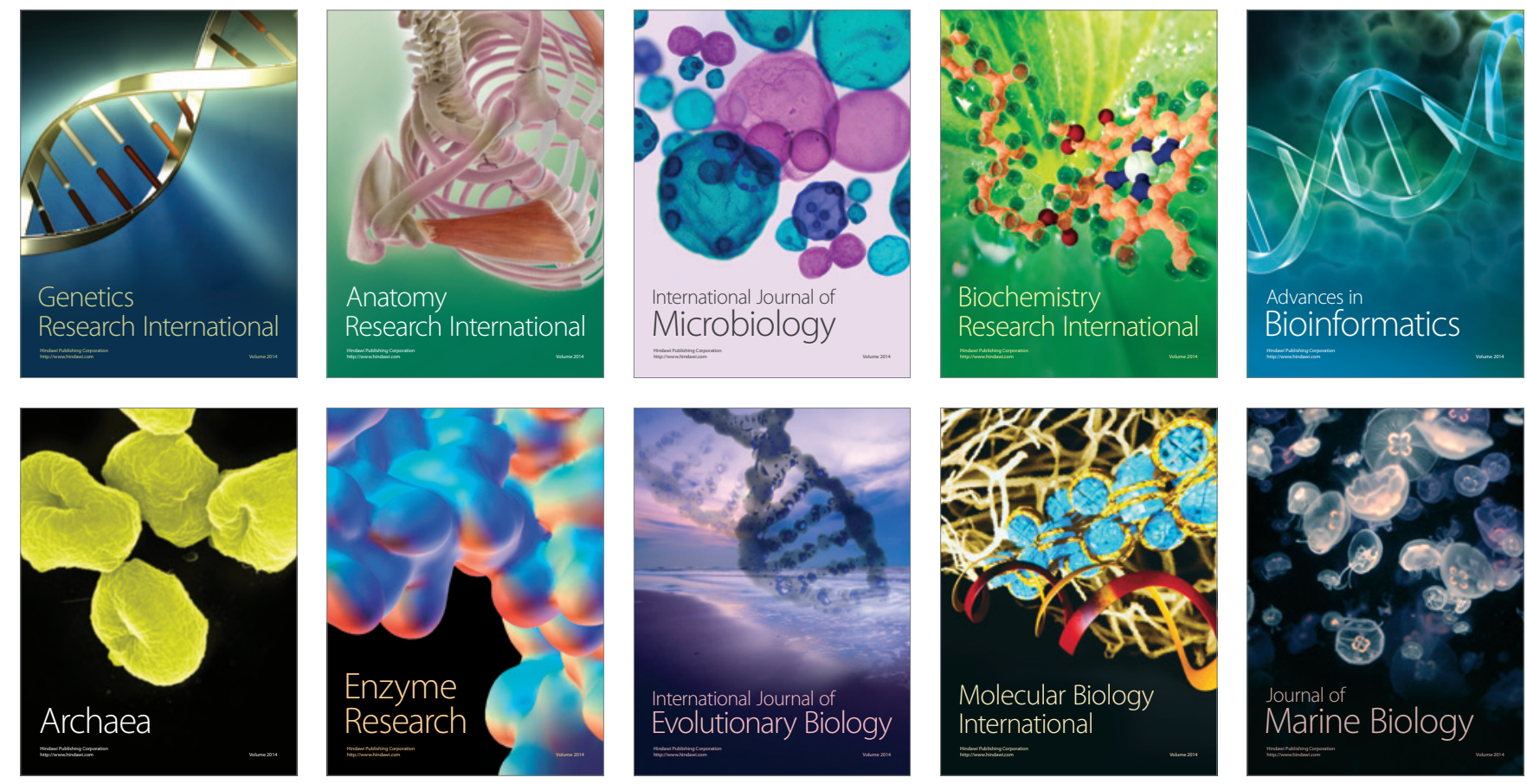